\title{
Cerebral oxygen delivery is reduced in newborns with congenital heart disease
}

\author{
Jessie Mei Lim, BSc, ${ }^{\mathrm{a}}$ Theodore Kingdom, ${ }^{\mathrm{b}}$ Brahmdeep Saini, BEng, ${ }^{\mathrm{c}}$ Vann Chau, MD, ${ }^{\mathrm{d}}$ \\ Martin Post, PhD, DVM, ${ }^{a}$ Susan Blaser, MD, ${ }^{e}$ Christopher Macgowan, PhD, ${ }^{\mathrm{e}, \mathrm{f}}$ \\ Steven P. Miller, MD, ${ }^{\mathrm{d}, \mathrm{g}}$ and Mike Seed, $\mathrm{MD}^{\mathrm{g}, \mathrm{h}}$
}

\begin{abstract}
Objective: To investigate preoperative cerebral hemodynamics in newborns with congenital heart disease. We hypothesized that cerebral blood flow and oxygen delivery would be decreased in newborns with congenital heart disease compared with controls.
\end{abstract}

Methods: Using a "feed-and-sleep" approach to performing neonatal magnetic resonance imaging, we measured cerebral blood flow by using a slice prescription perpendicular to the right and left internal carotid arteries and basilar artery at the level of the clivus. We calculated brain volume by segmenting a 3-dimensional steady-state free procession acquisition of the whole brain, allowing quantification of cerebral blood flow indexed to brain volume. Cerebral oxygen delivery was calculated as the product of cerebral blood flow and preductal systemic arterial oxygen content obtained via a combination of conventional pulse oximetry and laboratory analysis of venous blood samples for hemoglobin concentration.

Results: A complete set of measurements were obtained in 32 newborns with heart disease and 31 controls. There was no difference in gestational age between the heart disease and control groups. There was no difference in cerebral blood flow compared with controls (103.5 \pm 34.0 vs $119.7 \pm 40.4 \mathrm{~mL} / \mathrm{min})$, whereas cerebral oxygen delivery was significantly lower in the congenital heart disease subjects ( $1881 \pm 625.7$ vs $\left.2712 \pm 915.7 \mathrm{~mL}_{\mathrm{O} 2} / \mathrm{min}\right)$. Ten newborns with congenital heart disease had diffuse excessive high signal intensity in their white matter and 2 had white matter injury whereas another 5 had both.

Conclusions: Newborns with unrepaired cyanotic congenital heart disease have decreased cerebral oxygen delivery due to arterial desaturation. If brain growth and development are adversely affected through oxygen conformance, our findings could have clinical implications in terms of timing of surgical repair. (J Thorac Cardiovasc Surg 2016;152:1095-103)

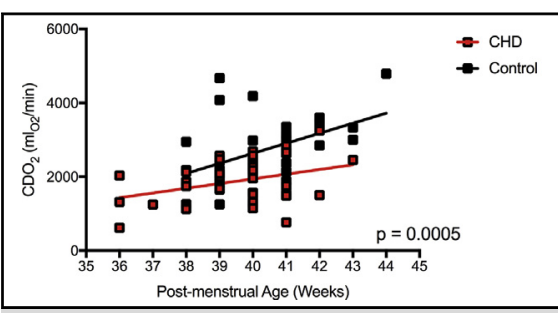

Cerebral oxygen delivery is significantly diminished in congenital heart disease.

\section{Central Message}

In preoperative newborns with cyanotic congenital heart disease, cerebral blood flow is maintained whereas cerebral oxygen delivery is decreased through arterial desaturation.

\section{Perspective}

This paper investigates preoperative cerebral hemodynamics in congenital heart disease, exploring the impact of cyanosis on cerebral oxygen delivery, which could have implications for the timing of surgical repair.

See Editorial page 960.
In recent decades, significant advances in cardiac surgical techniques have resulted in excellent survival rates for even the most complex forms of congenital heart disease

\footnotetext{
From the Departments of ahysiology, ${ }^{\mathrm{e}}$ Medical Imaging, ${ }^{\mathrm{f}}$ Medical Biophysics, ${ }^{\mathrm{g}}$ Pediatrics and ${ }^{\mathrm{h}}$ Diagnostic Imaging, and ${ }^{\mathrm{c}}$ Institute of Medical Science, University of Toronto; ${ }^{\mathrm{b}}$ McGill University, Montreal, Quebec; and ${ }^{\mathrm{d}}$ Department of Neurology, The Hospital for Sick Children, Toronto, Ontaria, Canada.

Supported by the Canadian Institutes of Health Research, Pediatric Heart Network (grant MOP93780).

Received for publication Feb 8, 2016; revisions received April 22, 2016; accepted for publication May 17, 2016; available ahead of print June 25, 2016.

Address for reprints: Mike Seed, MD, Departments of Pediatrics and Diagnostic Imaging, The Hospital for Sick Children, 555 University Ave, Toronto, ON M5G 1X8, Canada (E-mail: mike.seed@ sickkids.ca). $0022-5223 / \$ 36.00$

Copyright (c) 2016 by The American Association for Thoracic Surgery http://dx.doi.org/10.1016/j.jtcvs.2016.05.027
}

(CHD). Despite improvements in intraoperative brain protection, however, the neurodevelopmental outcomes of the survivors remain a serious cause for concern, and quantitative brain magnetic resonance imaging (MRI) findings point to delayed brain development and white matter injury (WMI) resulting from chronic preoperative cerebral hypoxia as a possible cause. ${ }^{1-5}$

Scanning this QR code will take you to the article title page. 


$$
\begin{aligned}
& \text { Abbreviations and Acronyms } \\
& \mathrm{BA}=\text { basilar artery } \\
& \mathrm{BV}=\text { brain volume } \\
& \mathrm{CBF}=\text { cerebral blood flow } \\
& \mathrm{CDO}_{2}=\text { cerebral oxygen delivery } \\
& \mathrm{CHD}=\text { congenital heart disease } \\
& \text { CoA }=\text { coarctation of the aorta } \\
& \text { DEHSI }=\text { diffuse excessive high signal intensity } \\
& \text { Hct = hematocrit } \\
& \mathrm{Hgb}=\text { hemoglobin } \\
& \text { MRI = magnetic resonance imaging } \\
& \mathrm{PC}=\text { phase contrast } \\
& \text { PMA }=\text { postmenstrual age } \\
& \text { SVP = single-ventricle physiology } \\
& \text { TGA }=\text { transposition of the great arteries } \\
& \mathrm{VA}=\text { vertebral artery } \\
& \text { WMI = white matter injury }
\end{aligned}
$$

Chronic hypoxia regulates cell metabolism through a mechanism known as oxygen conformance, whereby the cell protects itself against bioenergetic collapse by downregulating its oxygen requirement such that any reduction in oxygen delivery results in downstream effects on protein synthesis and cell cycling. ${ }^{6}$ In a murine model, oxygen tension recently has been shown to impact postnatal myelination through hypoxia-inducible factor, which regulates angiogenesis and the maturation of oligodendrocyte precursor cells. ${ }^{7}$ It is therefore possible that the rapid brain growth and development that normally occurs during early infancy could be adversely impacted by decreased cerebral oxygen delivery $\left(\mathrm{CDO}_{2}\right)$ that results from $\mathrm{CHD}$, particularly in those lesions that require a palliative or delayed surgical approach.

Previous studies in which the authors used optical measurements of tissue oxygenation and the MRI arterial spin labeling method have suggested that $\mathrm{CDO}_{2}$ and cerebral blood flow (CBF) are impaired in newborns with severe forms of $\mathrm{CHD}^{8,9}$; however, compensatory increases in $\mathrm{CBF}$ to maintain $\mathrm{CDO}_{2}$ in the setting of hypoxia have been described in human and animal fetuses and adults. ${ }^{10-12} \mathrm{~A}$ new approach to measuring $\mathrm{CBF}$ in newborns via the use of cine phase-contrast (PC) MRI has been described recently. ${ }^{13}$ We were interested in applying this technique to newborns with CHD in combination with conventional methods for measuring the oxygen content of blood and estimating brain volume (BV) to investigate cerebral hemodynamics in newborns with unrepaired CHD.

\section{METHODS \\ Subjects \\ The study design was a hospital research ethics board-approved, single-center prospective case control study conducted between June}

2013 and April 2015 at The Hospital for Sick Children in Toronto. The parents of consecutive children born with single-ventricle physiology (SVP), transposition of the great arteries (TGA), and coarctation of the aorta $(\mathrm{CoA})$ were invited to participate in the study. We defined subjects with SVP as those who were treated clinically on a palliative pathway to Fontan circulation. Preoperative imaging was arranged when the MRI was available and the clinical condition of the patient was suitable for an unsedated examination. Control subjects were drawn from a population of normal newborns born at Mount Sinai Hospital in Toronto during the same period.

Written consent was obtained from the parents of all subjects. We recruited 75 term newborns and all subjects were scanned in a 1.5-Tesla clinical MRI system (Siemens Avanto, Erlangen, Germany) before cardiac surgery at a mean age of $7.5 \pm 11$ days. The infants were fed and swaddled before imaging, and the scans were performed during sleep with no sedation or contrast medium using a 16-channel Siemens Pediatric Head Coil (Siemens Avanto, Erlangen, Germany).

\section{$\mathrm{CBF}$ and $\mathrm{CDO}_{2}$}

$\mathrm{CBF}$ was measured according to a previously published technique consisting of a single cine $\mathrm{PC}$ acquisition prescribed perpendicular to both internal carotid arteries and the basilar artery (BA) at the level of the clivus. ${ }^{13,14}$ The following scan parameters were used: echo time $=4.4 \mathrm{~ms}$, field of view $=150 \mathrm{~mm}$, matrix size $=150 \times 112$, slice thickness $=4 \mathrm{~mm}$, temporal resolution $=14.3 \mathrm{~ms}$, number of signal averages $=1$, velocity encoding $=150 \mathrm{~cm} / \mathrm{s}$ giving an in-plane resolution of $0.6 \times 0.6 \mathrm{~mm}$, and an acquisition time of 1 minute, 7 seconds. CBF volume was quantified with a commercial postprocessing tool (QFlow version 5.6; Medis, Leiden, The Netherlands).

In 14 patients, we obtained an additional PC acquisition in the neck, at the level of the larynx, which included imaging of the vertebral arteries (VAs) (Figure 1, A). Vessels were contoured manually by drawing points around the vessel circumference at each phase of the cardiac cycle and adjusted by the use of smoothing tools to yield vessel flows in $\mathrm{mL} / \mathrm{min}$. The arterial oxygen saturation was measured at the time of the PC acquisition by the use of conventional pulse oximetry with the probe applied to the right hand (model no. 2329; Masimo rainbow SET; Masimo Corp, Irvine, CA). The hemoglobin (Hgb) concentration was measured before MRI in all subjects with CHD, with samples obtained less than 8 days before imaging (mean interval 4 days). In control subjects, we were not permitted to obtain blood and used an estimated Hgb concentration of $17 \mathrm{~g} / \mathrm{dL}$ based on well-established reference data ${ }^{15,16}$ to calculate $\mathrm{CDO}_{2}$ as follows:

$$
\mathrm{CDO}_{2}=\mathrm{SaO}_{2} \times[\mathrm{Hgb}] \times 1.36 \times \mathrm{CBF}^{16}
$$

where 1.36 is the amount of oxygen bound per gram of $\mathrm{Hgb}$ at 1 atmosphere.

\section{BV and Brain Maturation}

To index net $\mathrm{CBF}$ and $\mathrm{CDO}_{2}$ measurements, $\mathrm{BV}$ was measured by segmenting the brain from a 3-dimensional steady-state free procession acquisition of the whole head (echo time $=2.0 \mathrm{~ms}$, repetition time $=4.5 \mathrm{~ms}$, field of view $=200$, matrix size $=192 \times 192$, slice thickness $=0.9 \mathrm{~mm}$, number of signal averages $=1$, parallel imaging factor $=1$, scan time $=37$ seconds), with the use of Mimics (Materialize, Leuven, Belgium), where brain tissue was isolated from cerebral spinal fluid within the ventricular system and around the brain in the extra-axial cerebrospinal fluid space by the use of thresholding and fine edited by the use of slice selection tools (Figure 1,B). BV was converted to brain weight with a conversion factor of $1.04 .{ }^{17}$ To assess WMI, diffuse excessive high signal intensity (DEHSI) in cerebral white matter was determined subjectively by a neuroradiologist in all subjects with CHD. Note was also made of any focal WMI or other abnormality. Furthermore, a total maturation score was evaluated by 2 observers (J.L., B.S.) blinded to 


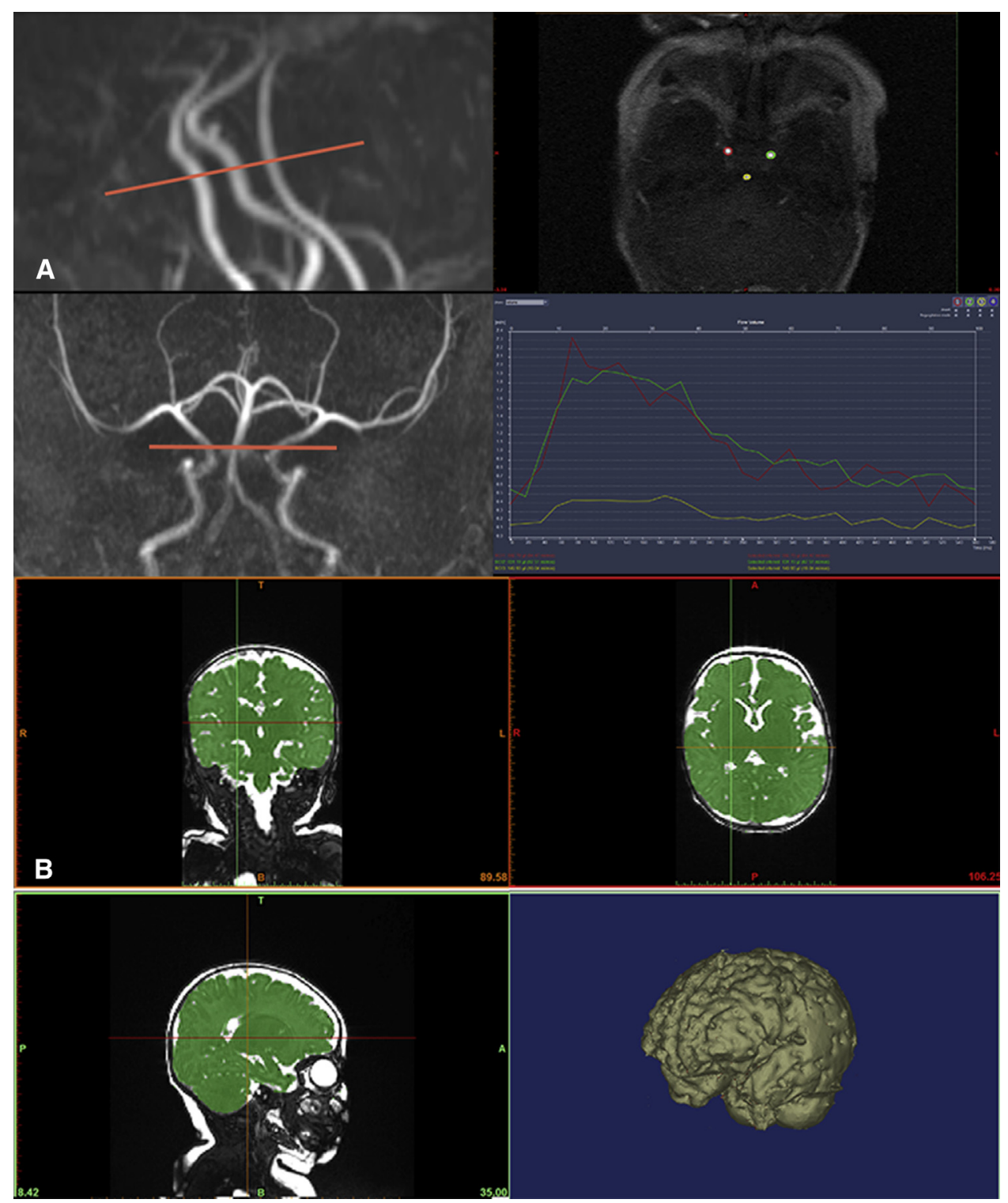

FIGURE 1. A, Slice prescription (left top and bottom images), vessel contours (top right), and flow profile (bottom right) for PC quantification of CBF. B, Manual segmentation of 3-dimensional steady-state free procession for calculation of BV (shown: coronal, axial, sagittal sections, and final 3D model).

clinical data for all subjects using a scoring system modified by Licht and colleagues. $^{18,19}$

\section{Statistical Analysis}

All statistical analyses were performed using GraphPad Prism 6.0e (GraphPad Software Inc, La Jolla, Calif). Pearson correlation and Bland-Altman plots were used to assess the level of interobserver agreement for vessel flow measurements and brain segmentation. The agreement between the sum of the flows in the right and left VA and flow in the BA was analyzed with the Pearson correlation. Net and indexed $\mathrm{CBF}$ and $\mathrm{CDO}_{2}$ values were compared in the 2 groups with an unpaired Student $t$ test. Linear regression analysis was performed to compare net and indexed $\mathrm{CBF}$ and $\mathrm{CDO}_{2}$ between the 2 groups against corrected gestational age. Regression analysis also was used to compare $\mathrm{CDO}_{2}$ to brain parameters. One-way analysis of variance was used to compare $\mathrm{CDO}_{2}$ between the subgroups of CHD with controls by use of the Tukey correction for multiple comparisons.

\section{RESULTS \\ Subjects}

Excessive movement artifact resulted in unacceptable image quality in 9 subjects (8 CHD subjects and 1 control), and 2 subjects with CHD were excluded after confirmation of a genetic syndrome. One subject with CHD passed away before imaging could be performed, allowing analysis of 63 complete datasets from the original 75 subjects recruited. There were 32 subjects with various forms of CHD and 31 age-matched controls. Twelve subjects CHD were managed surgically along a single-ventricle pathway, 4 had CoA, 13 had TGA, and 3 had other forms of CHD. In those that had SVP, 7 had hypoplastic left heart syndrome ( 2 with aortic atresia), 3 had tricuspid atresia, and 2 had 
TABLE 1. Demographics of patients with CHD

\begin{tabular}{|c|c|}
\hline Cardiac diagnosis & Number \\
\hline \multicolumn{2}{|l|}{ Single ventricle } \\
\hline Tricuspid atresia, single LV, VSD & 1 \\
\hline Tricuspid atresia, pulmonary atresia & 1 \\
\hline Left isomerism, pulmonary atresia & 1 \\
\hline Tricuspid atresia & 1 \\
\hline ccTGA, pulmonary atresia & 1 \\
\hline $\begin{array}{l}\text { Hypoplastic left ventricle, double-outlet } \\
\text { right ventricle with pulmonary atresia }\end{array}$ & 1 \\
\hline HLHS, mitral stenosis, aortic atresia & 1 \\
\hline HLHS, mitral atresia, aortic atresia & 2 \\
\hline HLHS, mitral stenosis, aortic stenosis & 2 \\
\hline $\begin{array}{l}\text { Hypoplastic left ventricle, ventriculo-arterial } \\
\text { discordance, pulmonary atresia }\end{array}$ & 1 \\
\hline \multicolumn{2}{|l|}{ Coarctation of the aorta } \\
\hline $\mathrm{CoA}$ & 2 \\
\hline CoA, BAV & 1 \\
\hline CoA, VSD & 1 \\
\hline \multicolumn{2}{|l|}{ TGA } \\
\hline TGA only & 9 \\
\hline TGA/VSD & 2 \\
\hline TGA/VSD, CoA & 1 \\
\hline Taussig-Bing anomaly & 1 \\
\hline \multicolumn{2}{|l|}{ Other } \\
\hline PA/IVS & 1 \\
\hline Tricuspid valve dysplasia & 2 \\
\hline
\end{tabular}

pulmonary atresia with intact ventricular septum. In those subjects with TGA, 4 had ventricular septal defects, 2 of whom also had aortic arch hypoplasia. In the group of other subjects with CHD, 2 had tricuspid valve dysplasia and 1 had pulmonary atresia with intact ventricular septum. A detailed list of diagnoses is given in Table 1 . The mean postmenstrual age (PMA) of all subjects was $39.8 \pm 1.7$ weeks and was not significantly different between CHD and controls (CHD $39.5 \pm 1.7$ weeks, controls $40.3 \pm 1.5$ weeks, $P=.07)$. Body weight between CHD and control subjects also was not statistically significant (CHD $3.3 \pm 0.5 \mathrm{~kg}$,

TABLE 2. Subject characteristics and mean values

\begin{tabular}{|c|c|c|c|c|c|c|c|}
\hline Subjects & $\begin{array}{c}\text { PMA, } \\
\text { wk }\end{array}$ & $\begin{array}{c}\mathrm{SaO}_{2}, \\
\%\end{array}$ & $\begin{array}{l}\mathrm{Hgb}, \\
\mathrm{g} / \mathrm{dL}\end{array}$ & $\begin{array}{c}\text { Het, } \\
\%\end{array}$ & $\begin{array}{c}\text { BW, } \\
\text { kg }\end{array}$ & $\begin{array}{l}\text { BV, } \\
\text { mL }\end{array}$ & TMS \\
\hline $\operatorname{Normal}(\mathrm{n}=31)$ & 40.4 & 98 & 17.0 & $30-42$ & 3.3 & 381.5 & 13.1 \\
\hline $\mathrm{CHD}(\mathrm{n}=32)$ & 39.5 & 87 & 15.2 & 46 & 3.3 & 336.1 & 11.2 \\
\hline $\operatorname{SVP}(\mathrm{n}=12)$ & 39.3 & 84 & 15.5 & 47 & 3.4 & 351.6 & 10.7 \\
\hline $\operatorname{CoA}(n=4)$ & 39.8 & 98 & 15.4 & 45 & 3.2 & 354.5 & 11.4 \\
\hline TGA $(\mathrm{n}=13)$ & 39.8 & 86 & 14.7 & 44 & 3.4 & 327.2 & 11.4 \\
\hline Other $(\mathrm{n}=3)$ & 38.7 & 93 & 16.1 & 48 & 3.0 & 313.7 & 12.0 \\
\hline
\end{tabular}

$\mathrm{PMA}$, Postmenstrual age; $\mathrm{SaO}_{2}$, arterial saturation; $\mathrm{Hgb}$, hemoglobin; $\mathrm{Hct}$, hematocrit; $B W$, body weight; $B V$, brain volume; $T M S$, total maturation score; $C H D$, congenital heart disease; $S V P$, single-ventricle physiology; $C o A$, coarctation of the aorta; $T G A$, transposition of the great arteries. controls $3.2 \pm 0.4 \mathrm{~kg}, P=.4)$. Grouped subject characteristics and mean values are listed in Table 2.

\section{$\mathrm{CBF}, \mathrm{CDO}_{2}$, and $\mathrm{BV}$}

There was a high degree of agreement between BA and VA flow sums in 14 control subjects, suggesting good consistency and accuracy of our method for measuring $\mathrm{CBF}\left(\mathrm{R}^{2}=0.70\right.$, $P=.0002)$. There also was high interobserver agreement for flow measurements $\left(\mathrm{R}^{2}=0.86, P=<.0001\right)$ and $\mathrm{BV}\left(\mathrm{R}^{2}=0.86, P=<.0001\right)$ without significant bias (Figure 2).

A comparison of net and indexed values of CBF performed with an unpaired Student $t$ test revealed there was no significant difference in CBF between the 2 groups. The mean net CBF in CHD subjects was $103.5 \pm 34.0 \mathrm{~mL} / \mathrm{min}$, whereas the mean in controls was $119.7 \pm 40.4 \mathrm{~mL} / \mathrm{min}(P=.09)$. CBF indexed to BV yielding indexed blood flow in CHD and control subjects was $29.1 \pm 6.7 \mathrm{~mL} \cdot \mathrm{min}^{-1} \cdot 100 \mathrm{~g}^{-1}$ and $30.3 \pm 8.7 \mathrm{~mL} \cdot \mathrm{min}^{-1} \cdot 100 \mathrm{~g}^{-1}$, respectively $(P=.6)$. Linear regression analysis revealed a relationship between PMA and CBF (net and indexed), and the elevation between the 2 groups was not significantly different $(P=.3$ for elevation differences in net $\mathrm{CBF}, P=.9$ for elevation differences in indexed CBF) (Figure 3).

On the basis of our confirmation of no significant difference in PMA between the groups, we compared net and indexed $\mathrm{CDO}_{2}$ using a Student $t$ test and showed that $\mathrm{CDO}_{2}$ in subjects with $\mathrm{CHD}$ was significantly lower than in normal controls. Mean net $\mathrm{CDO}_{2}$ in the $\mathrm{CHD}$ group was $1881 \pm 625.7 \mathrm{~mL} \mathrm{O}_{2} / \mathrm{min}$, whereas in control subjects, mean net $\mathrm{CDO}_{2}$ was $2712 \pm 915.7 \mathrm{~mL}_{\mathrm{O} 2} / \mathrm{min}(P=<.0001)$. When $\mathrm{CDO}_{2}$ was indexed to $\mathrm{BV}$ yielding indexed oxygen delivery, the difference between CHD and control subjects remained significant. Indexed mean $\mathrm{CDO}_{2}$ in $\mathrm{CHD}$ was $523.1 \pm 144.2 \mathrm{~mL}_{\mathrm{O} 2} \cdot \mathrm{min}^{-1} \cdot 100 \mathrm{~g}^{-1}$ and $685.6 \pm 201.9$ $\mathrm{mL}_{\mathrm{O} 2} \cdot \mathrm{min}^{-1} \cdot 100 \mathrm{~g}^{-1}$ in controls $(P=.0006)$. Linear regression analysis revealed a positive relationship between PMA and $\mathrm{CDO}_{2}$ and a significant difference in elevation between the 2 groups $(P=.0005$ for elevation in net values, $P=.002$ for elevation in indexed values) (Figure 3). There were significant differences between SVP, TGA, CoA, and controls in terms of mean net $\mathrm{CDO}_{2}$ $(P=.0005$, 1-way analysis of variance) with SVP and TGA groups having significantly lower $\mathrm{CDO}_{2}$ than control subjects (Figure 4, A), and no significant difference in age within subgroups. All statistical results are summarized in Table 3.

We demonstrated a significant difference between $\mathrm{BV}$ in the CHD and control groups, with BVs lower in subjects with CHD (CHD mean BV $338.5 \pm 47.8 \mathrm{~mL}$, control mean BV $377.7 \pm 47.1 \mathrm{~mL}, P=.002$ ). Conventional brain MRI revealed a combination of DEHSI and WMI in 5 subjects. An isolated finding of DEHSI was present in 10 CHD subjects, whereas 2 subjects with CHD had WMI 

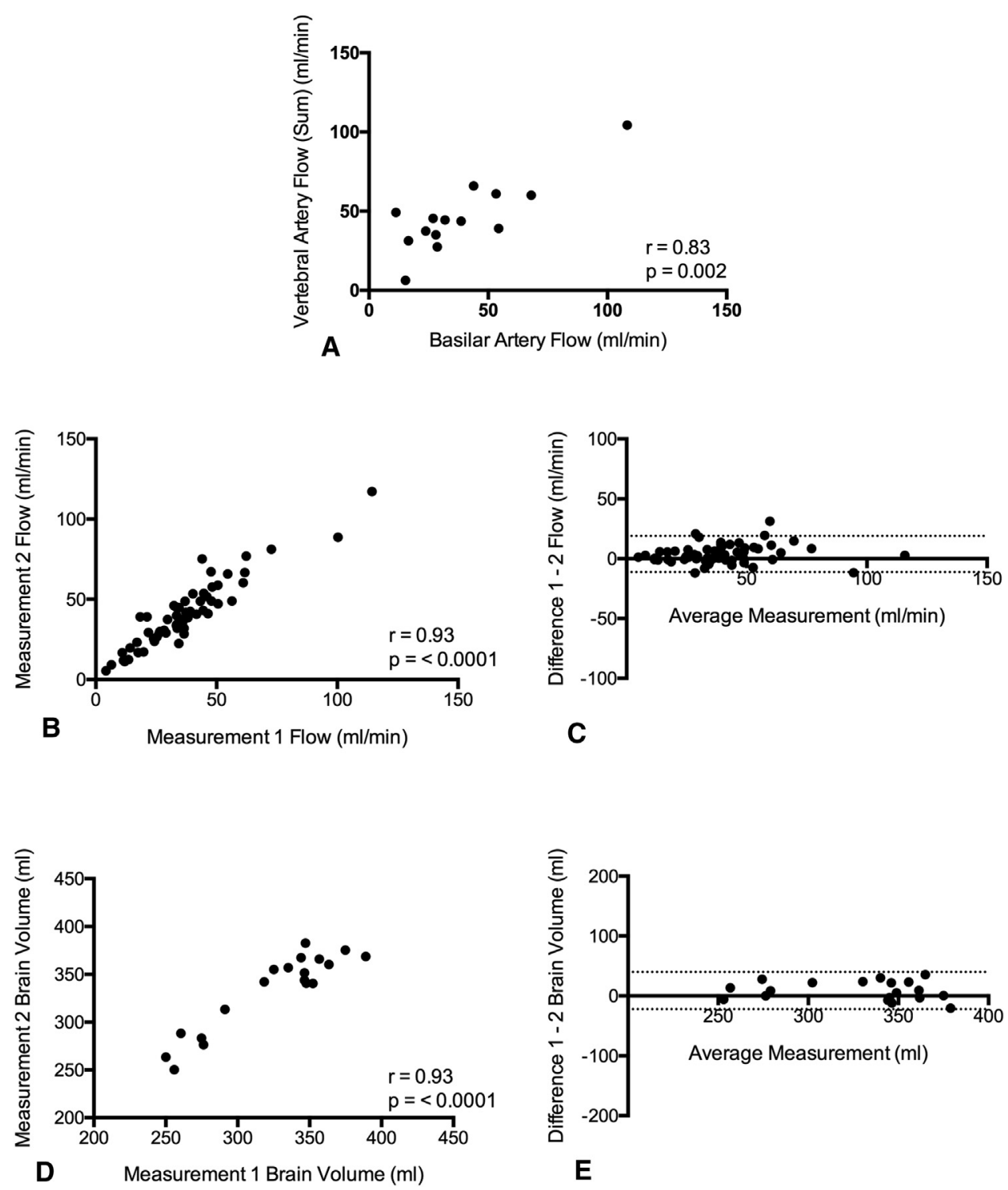

FIGURE 2. Flow agreement and interobserver variability for vessel flow and brain volume. A, Vertebral artery versus basilar artery. B and C, Vessel flow measurements. D and E, Brain volume measurements.

alone. Five subjects had other minor brain imaging abnormalities, such as small subdural hemorrhages. There were no abnormal findings on conventional brain MRI in the control subjects. There was no association between white matter changes and $\mathrm{CBF}$ or $\mathrm{CDO}_{2}$; however, there were significant correlations between net $\mathrm{CDO}_{2}$ and $\mathrm{BV}$ $\left(\mathrm{R}^{2}=0.4, P=<.0001\right)$ and $\mathrm{CDO}_{2}$ (net and indexed) and total maturation score (net: $\mathrm{R}^{2}=0.2, P=.0002$; indexed: $\mathrm{R}^{2}=0.2, P=.001$ ) (Figure $4, B-D$ ).

\section{DISCUSSION}

\section{CBF}

Quantitative MRI studies performed in preoperative neonates and adolescents after neonatal surgery for CHD reveal evidence of abnormal cerebral white matter microstructure and loss of BV..$^{1,4,20-22}$ Neuropathologic examinations of autopsy specimens indicate the etiology of these brain changes are likely to be chronic hypoxic ischemic injury (diffuse gliosis, periventricular leukomalacia), and quantitative neonatal MRI studies suggest these injuries are associated with abnormal brain growth and development. The cerebrovascular pathophysiology underlying these brain histopathologic and imaging abnormalities, however, is relatively poorly understood. Animal models suggest that $\mathrm{CDO}_{2}$ can be preserved in the setting of acute hypoxia through mechanisms affecting cerebral vasodilation, ${ }^{23-25}$ whereas in chronic hypoxia a compensatory increase in hematocrit 

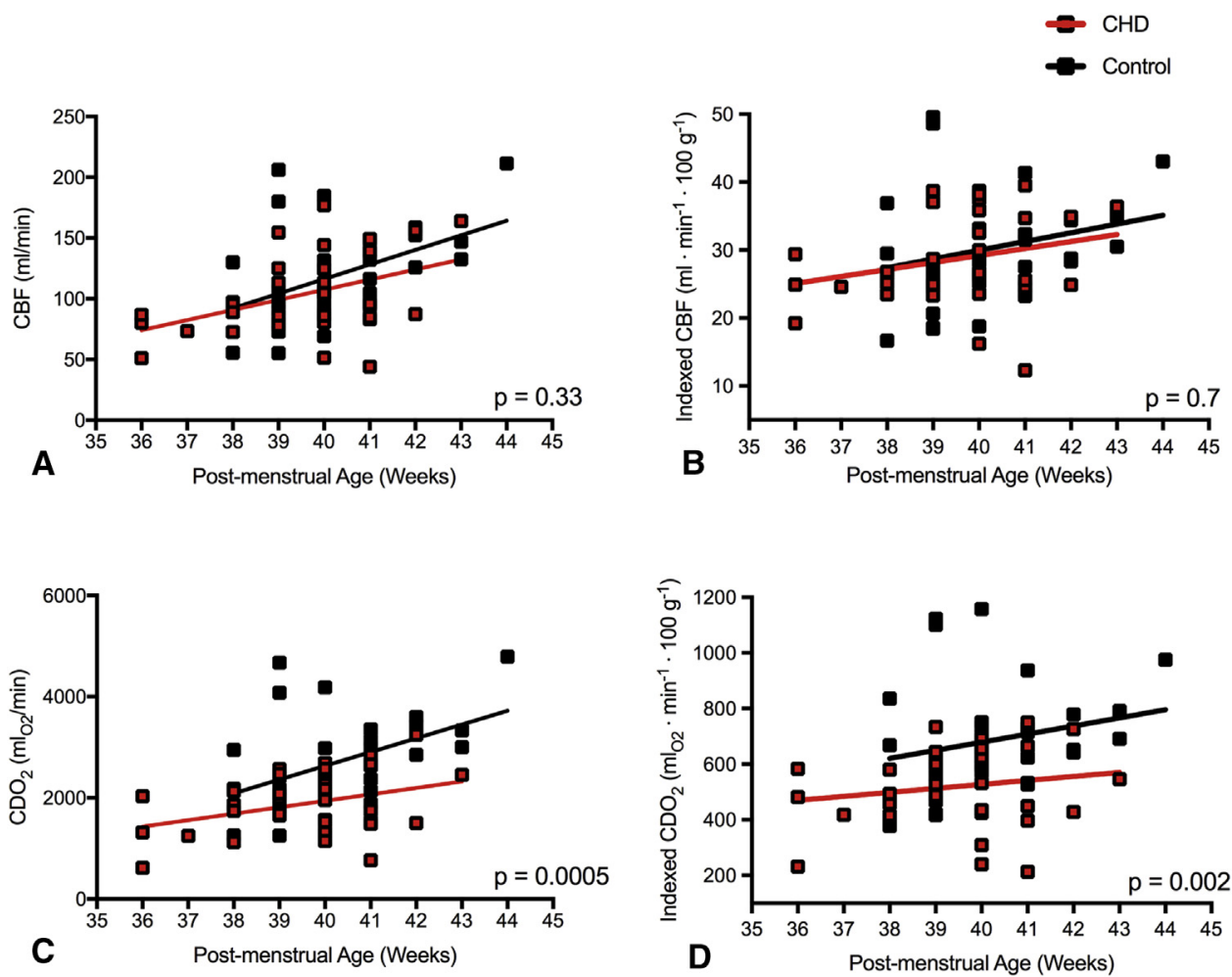

FIGURE 3. Linear regression of net and indexed CBF means between $\mathrm{CHD}$ and control groups against postmenstrual age. Bars indicate standard errors of the mean. $P$ values refer to the significant differences in regression line elevations. A, Net CBF; B, Indexed $\mathrm{CBF}_{\mathrm{C}} \mathrm{C}, \mathrm{Net}_{\mathrm{CDO}} ; \mathrm{D}_{\mathrm{Index}} \mathrm{IndO} \mathrm{C}_{2}$. $C B F$, Cerebral blood flow; $\mathrm{CHD}$, congenital heart disease; $\mathrm{CDO}_{2}$, cerebral oxygen delivery.

(Hct) allows some resolution of "brain-sparing" physiology. ${ }^{10,26}$ In these models, CBF varies inversely with Hct, either because of vasodilatory responses to changes in oxygen content or shear-related vessel responses from changes in viscosity. ${ }^{24}$ These models, however, are unlikely to fully characterize the impact of a range of abnormal hemodynamic patterns seen in unrepaired neonatal CHD during this critical period of brain development. Previous MRI studies that used arterial spin labeling have suggested that $\mathrm{CBF}$ and cerebral oxygen consumption are diminished in newborns with CHD, whereas our previous MRI study in late-gestation fetuses found ascending aortic desaturation with normal $\mathrm{CBF}$ and oxygen extraction, resulting in reductions in $\mathrm{CDO}_{2}$ and consumption that were associated with diminished brain growth. ${ }^{8,9,27}$ In the current study of neonates with CHD, we also found CBF in neonates with $\mathrm{CHD}$ to be normal, with reductions in $\mathrm{CDO}_{2}$ resulting from a reduction in the oxygen content of blood supplied to the cerebral circulation, more in keeping with the cerebral hemodynamic picture we observed in fetuses with CHD.

The reason for the discrepancy between our findings and those found by other groups may reflect differences in the study populations (previous studies had a preponderance of subjects with hypoplastic left heart syndrome, in whom upstream anatomical obstruction could limit CBF, whereas in our study only 2 subjects had aortic atresia), differing physiology between anesthetized and unsedated subjects, and the differing techniques used to measure CBF (arterial spin labeling is known to be vulnerable to underestimation from insensitivity to low arterial transit times seen in neonates, while the accuracy of cine PC is limited in small vessels). ${ }^{28,29}$

In our population, Hct levels were only slightly elevated, compared with increases of greater than $20 \%$ seen in fetal animal studies of chronic hypoxia. ${ }^{26,30}$ This finding is in keeping with the normal $\mathrm{Hgb}$ concentrations seen in newborns with CHD, which actually tend to be lower than the normal mean. Rudolph and colleagues ${ }^{31,32}$ described this absence of polycythemia in newborns with CHD as a "relative anemia," defined as an incidence of polycythemia that was insufficient for adaptation to hypoxia. In their study, Hct increased in mildly cyanotic $\mathrm{CHD}$, whereas $\mathrm{Hgb}$ levels were normal. In severely cyanotic CHD, there was a complete divergence between Hct and Hgb levels. ${ }^{32}$ Thus, unlike the familiar and tightly regulated adaptations to chronic hypoxia seen in animal models, newborns with CHD appear to be lacking a compensatory increase in Hct and $\mathrm{Hgb}$, which may imply an anemic-like state. In our population, there was no 

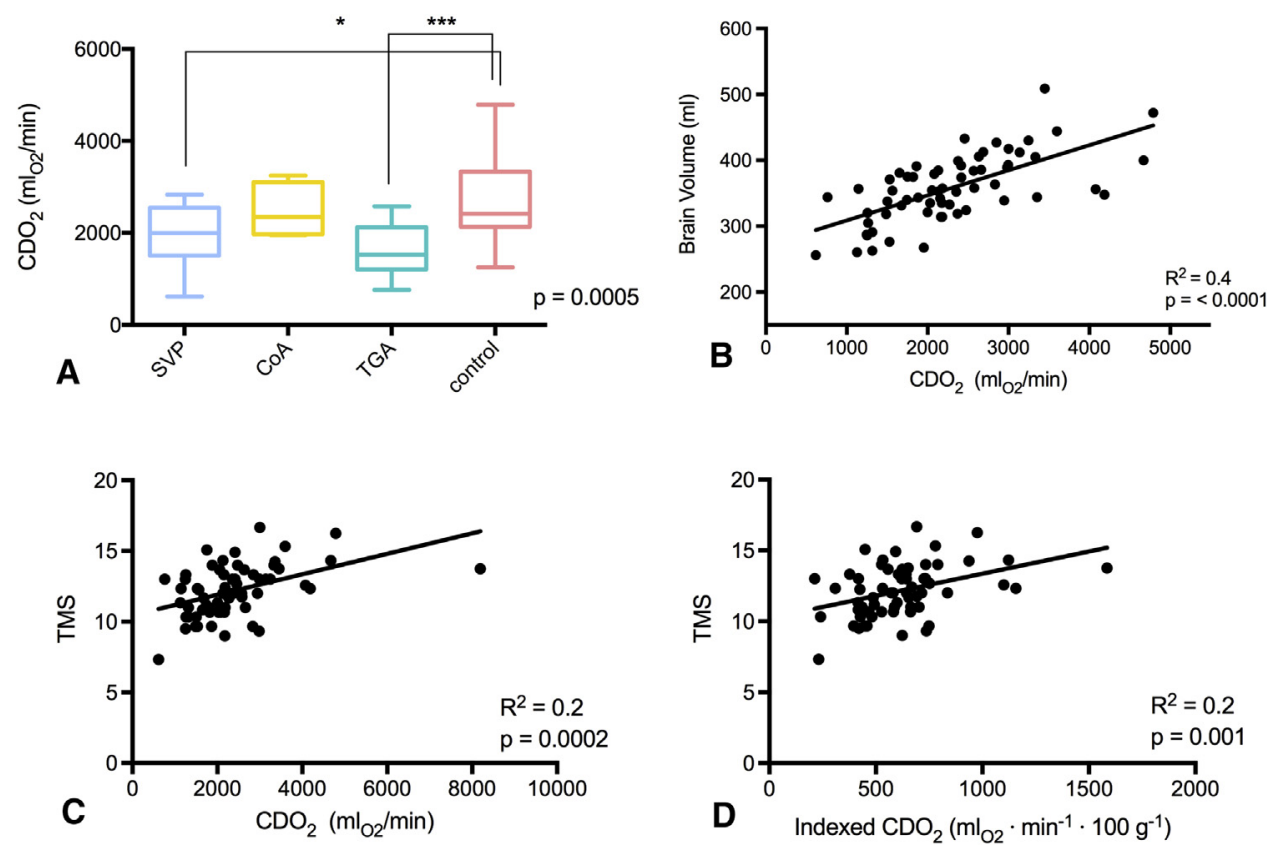

FIGURE 4. A, Comparison of $\mathrm{CDO}_{2}$ within $\mathrm{CHD}$ subgroups SVP, CoA, and TGA. *Indicates level of significant difference to control. B, Correlation of brain volume to net $\mathrm{CDO}_{2}$. C, Correlation of net $\mathrm{CDO}_{2}$ to TMS. D, Correlation of indexed $\mathrm{CDO}_{2}$ to TMS. $C D O_{2}$, Cerebral oxygen delivery; $S V P$, singleventricle physiology; $C o A$, coarctation of the aorta; TGA, transposition of the great arteries; TMS, total maturation score. $* P<.03$ and $* * * P<.0002$.

evidence of anemia (mean cell $\mathrm{Hgb}$ was within normal range and red blood cell size was normal), although $\mathrm{Hgb}$ concentrations were towards the lower end of normal.

\section{$\mathrm{CDO}_{2}$}

Our cohort of CHD newborns had significantly lower $\mathrm{CDO}_{2}$ (both in net value and indexed values) than the control group. In both animal and human models, $\mathrm{CDO}_{2}$ is usually strictly maintained throughout acute and chronic hypoxia. ${ }^{10,24}$ In chronically hypoxic ischemic fetal lambs, however, $\mathrm{CDO}_{2}$ remains low postnatally despite the normalization of $\mathrm{CBF}^{33}$ Cells exposed to chronic hypoxia are known to demonstrate oxygen conformance, a process resulting in down regulation of mitochondrial respiration which is associated with a reduction of oxygen consumption. Bioenergetic sacrifices in the supply and demand of ATP have important cellular consequences, one of which is the inhibition of protein translation during growth factor stimulation. ${ }^{6}$ In mice, oxygen tension also influences glial cell maturation and angiogenesis through hypoxic inducible factor. ${ }^{7}$ The precise cellular mechanisms affected by oxygen conformance are outside the scope of this paper, but it would appear likely that these have important implications for the growth, maturation and development of the brain in early life. We found that $\mathrm{CDO}_{2}$ was associated with greater brain size and maturity. A causal relationship has not been established, however, our results raise the possibility of a link between fetal brain development and neonatal hemodynamics. In contrast, the poor correlation between DEHSI and hemodynamic measures may reflect the subjective and nonspecific nature of this observation. Cerebral growth in the first year is likely to be important for development in children born with $\mathrm{CHD},{ }^{34}$ as head circumference and $\mathrm{BV}$ are associated with subsequent intelligence quotient. ${ }^{35}$ Our finding of reduced BV in newborns with CHD is in keeping with other studies in which the authors demonstrated impaired brain maturation with a variety of brain metrics and further supports the hypothesis that unrepaired CHD impacts brain development, even before birth. ${ }^{4,36,37}$

Among our CHD subgroups, SVP and TGA demonstrated the most significant reductions in $\mathrm{CDO}_{2}$. This finding is to be expected, because these are 2 types of CHD well-known to be significantly cyanosed before surgical repair or palliation. Importantly, these are the 2 groups of patients whose neurodevelopmental outcomes have been most studied extensively and found to have a range of deficits, starting with delayed motor development in infancy and encompassing a range of neurocognitive problems by adolescence. ${ }^{38,39}$ In our cohort, a large proportion of SVP and TGA also had DEHSI or WMI. We suspect that persistently low oxygen delivery in fetal life and before surgical repair results in cerebral metabolic adaptation with ultimate effects on brain maturation. Our study did not include any measure of cerebral oxygen consumption, but this could be possible using methods such as T2 relaxation under spin-tagging (ie, TRUST) ${ }^{40}$ Such an approach may provide important 
TABLE 3. Summary of statistical results

\begin{tabular}{|c|c|c|c|}
\hline \multirow[b]{2}{*}{ Results } & \multicolumn{2}{|c|}{ Subject group } & \multirow{2}{*}{$\begin{array}{c}P \\
\text { Value } \\
\end{array}$} \\
\hline & CHD & Control & \\
\hline \multicolumn{4}{|l|}{ Student $t$ test } \\
\hline Net CBF, mL/min & $103.5 \pm 34.0$ & $119.7 \pm 40.4$ & .09 \\
\hline $\begin{array}{l}\text { Indexed CBF, } \mathrm{mL} \cdot \\
\quad \min ^{-1} \cdot 100 \mathrm{~g}^{-1}\end{array}$ & $29.1 \pm 6.7$ & $30.3 \pm 8.7$ & .7 \\
\hline Net $\mathrm{CDO}_{2}, \mathrm{~mL}_{\mathrm{O} 2} / \mathrm{min}$ & $1881 \pm 625.7$ & $2712 \pm 915.7$ & $<.0001$ \\
\hline $\begin{array}{l}\text { Indexed } \mathrm{CDO}_{2}, \mathrm{~mL}_{\mathrm{O} 2} \\
\min ^{-1} \cdot 100 \mathrm{~g}^{-1}\end{array}$ & $523.1 \pm 144.2$ & $685.6 \pm 201.9$ & .002 \\
\hline $\mathrm{BV}, \mathrm{mL}$ & $338.5 \pm 47.8$ & $377.7 \pm 47.1$ & .002 \\
\hline \multicolumn{4}{|l|}{$\begin{array}{l}\text { Linear regression } \\
\quad \text { (against PMA) }\end{array}$} \\
\hline \multicolumn{4}{|l|}{ Net CBF } \\
\hline Slope & $8.32 \pm 3.22$ & $12.0 \pm 4.36$ & .5 \\
\hline$y$-intercept & $-226 \pm 127$ & $-364 \pm 176$ & .3 \\
\hline \multicolumn{4}{|l|}{ Indexed CBF } \\
\hline Slope & $1.03 \pm 0.71$ & $1.29 \pm 1.05$ & .8 \\
\hline y-intercept & $-11.96 \pm 28.2$ & $-21.45 \pm 42.3$ & .7 \\
\hline \multicolumn{4}{|l|}{ Net $\mathrm{CDO}_{2}$} \\
\hline Slope & $127 \pm 61.3$ & $272 \pm 98.9$ & .2 \\
\hline y-intercept & $-3158 \pm 2428$ & $-8250 \pm 3985$ & .0005 \\
\hline \multicolumn{4}{|l|}{ Indexed $\mathrm{CDO}_{2}$} \\
\hline Slope & $14.3 \pm 15.5$ & $29.1 \pm 23.8$ & .6 \\
\hline y-intercept & $-46.2 \pm 614$ & $-487 \pm 959$ & .002 \\
\hline \multicolumn{4}{|l|}{ ANOVA w/Tukey } \\
\hline Subgroup $\mathrm{CDO}_{2}$ & & & .0005 \\
\hline \multicolumn{4}{|l|}{$\begin{array}{l}\text { Pearson correlation } \\
\quad \text { (against } \mathrm{CDO}_{2} \text { ) }\end{array}$} \\
\hline$B V$ & & & $<.0001$ \\
\hline TMS & & & .0002 \\
\hline $\begin{array}{l}\text { TMS (against } \\
\text { indexed } \mathrm{CDO}_{2} \text { ) }\end{array}$ & & & .001 \\
\hline
\end{tabular}

$\overline{C H D}$, Congenital heart disease; $\mathrm{CBF}$, cerebral blood flow; $\mathrm{CDO}_{2}$, cerebral oxygen delivery; $B V$, brain volume; $P M A$, postmenstrual age; $A N O V A$, analysis of variance; $T M S$, total maturation score. Bolded $P$ values indicate statistical significance.

insights into the relationships between cerebrovascular physiology and brain growth and development in CHD in the future. The precise connection between cellular responses to hypoxia and neurodevelopmental outcomes has not been established, and we propose this relationship merits further investigation, particularly as there may be implications for the management of oxygenation and surgical timing to improve neurodevelopmental outcomes.

\section{Sensitivity Analysis and Limitations}

We were not permitted to perform hematologic analysis in our control group, obliging us to assume certain parameters based on reference data. Specifically, we assumed a normal mean $\mathrm{Hgb}$ concentration of $17 \mathrm{~g} / \mathrm{dL}$ in our controls. As part of a sensitivity analysis, we repeated our analysis using the same $\mathrm{Hgb}$ concentration of $15 \mathrm{~g} / \mathrm{dL}$ that we obtained from the hematology in the subjects with CHD. The difference in $\mathrm{CDO}_{2}$ between our groups remained significant, supporting our hypothesis that the reduction we found in $\mathrm{CDO}_{2}$ was a true finding, attributable to the reduction in oxygen saturation of blood supplied to the brain and not a reduction in $\mathrm{Hgb}$. Furthermore, it is recognized that some $\mathrm{Hgb}$ measurements were not taken on the same day as the scan, and daily fluctuations may allow nuances in our calculations of $\mathrm{CDO}_{2}$. These fluctuations, however, were small and it is unlikely that these small differences impact our calculations.

Unlike a conventional blood gas analysis, pulse oximetry does not account for dissolved oxygen in the plasma. Dissolved oxygen is approximately $0.3 \mathrm{~mL} / \mathrm{dL}$ at a $\mathrm{PO}_{2}$ of $100 \mathrm{~mm} \mathrm{Hg}$ (100\% saturation). ${ }^{16}$ Subjects in our cohort have an average saturation of $87 \%$ and at lower levels of $\mathrm{PO}_{2}$ the amount of dissolved oxygen becomes negligible, and it would therefore seem reasonable to ignore the trivial contribution of oxygen dissolved in plasma to blood oxygen content.

The small size of the head and neck vessels in neonates poses a challenge to the accuracy of $\mathrm{CBF}$ quantification with cine PC imaging. Our in-plane spatial resolution was established based on the previously described approach to measuring CBF in neonates $(0.6 \times 0.6 \mathrm{~mm}),{ }^{13}$ which optimizes the balance between resolving the flow velocity across the vessel lumen and obtaining adequate signal. The average diameter of a neonatal internal carotid artery is $1.3 \mathrm{~mm}$, allowing for approximately 4 voxels across the vessel area. ${ }^{41}$ We used a temporal resolution of approximately $15 \mathrm{~ms}$, which achieves approximately 30 true cardiac phases in these neonates with average heart rates of 135 beats per minute, which is likely to be more than adequate to achieve accurate flow measurements.

\section{CONCLUSION}

In this work, we quantified the $\mathrm{CBF}$ and oxygen delivery in newborns with CHD by using PC MRI, conventional pulse oximetry, and laboratory hematology. CBF was found to be similar to that in our control group, but $\mathrm{CDO}_{2}$ was significantly decreased in CHD newborns, with SVP and TGA newborns the most significantly affected. Although the impact of this reduction in $\mathrm{CDO}_{2}$ is not known, theoretical reasons for thinking it might adversely impact ongoing brain growth and development during this period of rapid brain growth are considered. Further support for the concept that such a mechanism could lead to irreversible deficits in brain growth and development might result in attempts to expedite surgical repair of congenital cardiac lesions, which have conventionally not been addressed in the neonatal period.

\section{Conflict of Interest Statement}

Authors have nothing to disclose with regard to commercial support. 


\section{References}

1. Miller SP, McQuillen PS, Hamrick S, Xu D, Glidden DV, Charlton N, et al. Abnormal brain development in newborns with congenital heart disease. N Engl J Med. 2007;357:1928-38.

2. McQuillen PS, Miller SP. Congenital heart disease and brain development. Ann N Y Acad Sci. 2010;1184:68-86

3. Block A, McQuillen P, Chau V, Glass H, Poskitt KJ, Barkovich AJ, et al. Clinically silent preoperative brain injuries do not worsen with surgery in newborns with congenital heart disease. J Thorac Cardiovasc Surg. 2010;140: $550-7$.

4. von Rhein M, Buchmann A, Hagmann C, Dave H, Bernet V, Scheer I, et al. Severe congenital heart defects are associated with global reduction of neonatal brain volumes. J Pediatr. 2015;167:1259-63.e1.

5. Limperopoulos C, Majnemer A, Shevell MI, Rosenblatt B, Rohlicek C, Tchervenkov C, et al. Functional limitations in young children with congenital heart defects after cardiac surgery. Pediatrics. 2001;108:1325-31.

6. Wheaton WW, Chandel NS. Hypoxia. 2. Hypoxia regulates cellular metabolism. Am J Physiol Cell Physiol. 2011;300:C385-93.

7. Yuen TJ, Silbereis JC, Griveau A, Chang SM, Daneman R, Fancy SPJ, et al. Oligodendrocyte-encoded HIF function couples postnatal myelination and white matter angiogenesis. Cell. 2014;158:383-96.

8. Licht DJ, Wang J, Silvestre DW, Nicolson SC, Montenegro LM, Wernovsky G, et al. Preoperative cerebral blood flow is diminished in neonates with severe congenital heart defects. J Thorac Cardiovasc Surg. 2004;128:841-9.

9. Dehaes M, Cheng HH, Buckley EM, Lin PY, Ferradal S, Williams K, et al. Perioperative cerebral hemodynamics and oxygen metabolism in neonates with single-ventricle physiology. Biomed Opt Express. 2015;6:4749-67.

10. Xu K, Lamanna JC. Chronic hypoxia and the cerebral circulation. J Appl Physiol (1985). 2006;100:725-30

11. Cohn HE, Sacks EJ, Heymann MA, Rudolph AM. Cardiovascular responses to hypoxemia and acidemia in fetal lambs. Am J Obstet Gynecol. 1974;120:817-24.

12. Salihagić-Kadić A, Medić M, Jugović D, Kos M, Latin V, Kusan Jukić M, et al. Fetal cerebrovascular response to chronic hypoxia-implications for the prevention of brain damage. J Matern Neonatal Med. 2006;19:387-96.

13. Varela M, Groves AM, Arichi T, Hajnal JV. Mean cerebral blood flow measurements using phase contrast MRI in the first year of life. NMR Biomed. 2012;25:1063-72.

14. Macgowan CK, Chan KY, Laughlin S, Marrie RA, Banwell B. Cerebral arterial and venous blood flow in adolescent multiple sclerosis patients and age-matched controls using phase contrast MRI. J Magn Reson Imaging. 2014;40:341-7.

15. Jopling J, Henry E, Wiedmeier SE, Christensen RD. Reference ranges for hematocrit and blood hemoglobin concentration during the neonatal period: data from a multihospital health care system. Pediatrics. 2009;123:e333-7.

16. Rudolph AM. Congenital Diseases of the Heart. 3rd ed. West Sussex: Wiley-Blackwell; 2009.

17. Roelfsema NM, Hop WCJ, Boito SME, Wladimiroff JW. Three-dimensional sonographic measurement of normal fetal brain volume during the second half of pregnancy. Am J Obstet Gynecol. 2004;190:275-80.

18. Childs AM, Ramenghi LA, Cornette L, Tanner SF, Arthur RJ, Martinez D, et al. Cerebral maturation in premature infants: quantitative assessment using MR imaging. AJNR Am J Neuroradiol. 2001;22:1577-82.

19. Licht DJ, Shera DM, Clancy RR, Wernovsky G, Montenegro LM, Nicolson SC, et al. Brain maturation is delayed in infants with complex congenital heart defects. J Thorac Cardiovasc Surg. 2009;137:529-36; discussion 536-537.

20. von Rhein M, Buchmann A, Hagmann C, Huber R, Klaver P, Knirsch W, et al. Brain volumes predict neurodevelopment in adolescents after surgery for congenital heart disease. Brain. 2014;137:268-76.

21. Rivkin MJ, Watson CG, Scoppettuolo LA, Wypij D, Vajapeyam S, Bellinger DC, et al. Adolescents with D-transposition of the great arteries repaired in early infancy demonstrate reduced white matter microstructure associated with clinical risk factors. J Thorac Cardiovasc Surg. 2013;146: 543-9.
22. Owen M, Shevell M, Donofrio M, Majnemer A, McCarter R, Vezina G, et al Brain volume and neurobehavior in newborns with complex congenital hear defects. J Pediatr. 2014;164:1121-7.e1.

23. Hudak ML, Koehler RC, Rosenberg AA, Traystman RJ, Jones MD Jr. Effect of hematocrit on cerebral blood flow. Am J Physiol. 1986;251:H63-70.

24. Jones MD, Traystman RJ, Simmons MA, Molenti RA. Effects of changes in arterial O2 content on cerebral blood flow in the lamb. Am J Physiol. 1981; 240:H209-15.

25. Todd MM, Wu B, Maktabi M, Hindman BJ, Warner DS. Cerebral blood flow and oxygen delivery during hypoxemia and hemodilution: role of arterial oxygen content. Am J Physiol. 1994;267:H2025-31.

26. LaManna JC, Vendel LM, Farrell RM. Brain adaptation to chronic hypobaric hypoxia in rats. $J$ Appl Physiol. 1992;72:2238-43.

27. Sun L, Macgowan CK, Sled JG, Yoo S-J, Manlhiot C, Porayette P, et al. Reduced fetal cerebral oxygen consumption is associated with smaller brain size in fetuses with congenital heart disease. Circulation. 2015;131:1313-23.

28. Petersen ET, Zimine I, Ho Y-CL, Golay X. Non-invasive measurement of perfusion: a critical review of arterial spin labelling techniques. $\mathrm{Br} J$ Radiol. 2006;79:688-701.

29. Kleinman CS, Seri I. Hemodynamics and Cardiology: Neonatalogy Questions and Controversies. Philadelphia: Elsevier Inc; 2008.

30. Xu K, Puchowicz MA, LaManna JC. Renormalization of regional brain blood flow during prolonged mild hypoxic exposure in rats. Brain Res. 2004;1027: 188-91.

31. Amoozgar H, Soltani M, Besharati A, Cheriki S. Undiagnosed anemia in pediatric patients with congenital heart diseases. Iran Cardiovasc Res J. 2011; 5:69-70.

32. Rudolph AH, Nadas AS, Borges WH. Hematologic adjustments to cyanotic congenital heart disease. Pediatrics. 1953;11:454-64.

33. Rey-Santano C, Mielgo VE, Gastiasoro E, Murgia X, Lafuente $H$, Ruiz-del-Yerro E, et al. Early cerebral hemodynamic, metabolic, and histological changes in hypoxic-ischemic fetal lambs during postnatal life. Front Neurosci. 2011;5:1-12.

34. Daymont C, Neal A, Prosnitz A, Cohen MS. Growth in children with congenital heart disease. Pediatrics. 2013;131:e236-42.

35. Gale CR, O'Callaghan FJ, Bredow M, Martyn CN. The influence of head growth in fetal life, infancy, and childhood on intelligence at the ages of 4 and 8 years. Pediatrics. 2006;118:1486-92.

36. Ortinau C, Beca J, Lambeth J, Ferdman B, Alexopoulos D, Shimony JS, et al Regional alterations in cerebral growth exist preoperatively in infants with congenital heart disease. J Thorac Cardiovasc Surg. 2012;143:1264-70.

37. Limperopoulos C, Tworetzky W, McElhinney DB, Newburger JW, Brown DW, Robertson RL, et al. Brain volume and metabolism in fetuses with congenital heart disease: evaluation with quantitative magnetic resonance imaging and spectroscopy. Circulation. 2010;121:1-17.

38. Hinton RB, Andelfinger G, Sekar P, Hinton AC, Gendron RL, Michelfelder EC et al. Prenatal head growth and white matter injury in hypoplastic left heart syndrome. Pediatr Res. 2008;64:364-9.

39. Goldberg CS, Schwartz EM, Brunberg JA, Mosca RS, Bove EL, Schork MA, et al. Neurodevelopmental outcome of patients after the fontan operation: a comparison between children with hypoplastic left heart syndrome and other functional single ventricle lesions. J Pediatr. 2000;137:646-52.

40. Jain V, Buckley EM, Licht DJ, Lynch JM, Schwab PJ, Naim MY, et al. Cerebral oxygen metabolism in neonates with congenital heart disease quantified by MRI and optics. J Cereb Blood Flow Metab. 2014;34:380-8.

41. Sehirli ÜS, Yalin A, Tulay CM, Cakmak YO, Gürdal E. The diameters of common carotid artery and its branches in newborns. Surg Radiol Anat. 2005; 27:292-6.

Key Words: congenital heart disease, cerebral oxygen delivery, cerebral blood flow, preoperative management 